03

\title{
Столкновения капель жидкости разной формы в газовом потоке
}

\author{
(C) Г.В. Кузнецов, П.А. Стрижак" \\ Национальный исследовательский Томский политехнический университет,Томск, Россия \\ ฯ E-mail: pavelspa@tpu.ru
}

Поступило в Редакцию 9 августа 2018г.

В окончательной редакции 21 декабря 2018 r.

Принято к публикации 21 декабря 2018г.

\begin{abstract}
Представлены результаты экспериментальных исследований взаимодействия капель воды с разной конфигурацией поверхности в газовой среде. В результате высокоскоростной видеорегистрации получена информационная база данных по столкновениям (в режиме коагуляции, разлета, дробления) капель: сфер, сплюснутых и вытянутых эллипсоидов. Показано, что определяющее влияние оказывает конфигурация поверхности капель (помимо традиционных представлений о влиянии размеров, скоростей движения и угла атаки). Вычислены значения чисел Вебера для описания условий взаимодействия капель разной формы.
\end{abstract}

DOI: 10.21883/PJTF.2019.06.47494.17497

Современные представления о процессах столкновений капель жидкостей в газовой среде (отражены в монографиях [1-3]) сформированы на основе анализа результатов опытов, выполненных с применением двух подходов. В соответствии с первым (феноменологическим) проводится регистрация взаимодействия двух капель различных размеров, движущихся с разными скоростями $[4,5]$ (нередко одна капля находится в неподвижном состоянии за счет подвешивания на держателе, а вторая перемещается с заданной скоростью и траекторией). При втором (статистическом) подходе генерируется аэрозольное облако, и за счет выборки кадров составляется информационная база по количеству столкновений и вариантам их последствий, рассчитывается частота их реализации [6,7]. Основное внимание при проведении таких экспериментов уделяется контролю размеров, скоростей и траекторий движения, a также углов взаимодействия капель. Безразмерная обработка результатов экспериментов [4] позволяет получить типичные интервалы изменения чисел Вебера сталкивающихся капель, которые соответствуют коагуляции, разлету, дроблению (измельчению). Однако в соответствии с результатами опытов [8] можно сделать вывод, что капли жидкости в процессе полета непрерывно деформируются и принимают формы (шесть-восемь разных), существенно отличающиеся от сферы: каплевидные, эллипсоидальные и др. Интерес представляет анализ столкновений капель с разной конфигурацией поверхности.

В настоящей работе приведены результаты опытов, направленных на регистрацию различий характеристик столкновений капель воды с разной формой при их движении в воздухе. В отличие от экспериментов [6-8] использовалась схема с генерированием двух сонаправленных, движущихся навстречу и под углом $\pi / 2$ полидисперсных аэрозолей. Также выполнялось исследование условий столкновения капель при встречном смешении аэрозоля с потоком воздуха. Разные направления аэро- зольных и воздушных потоков необходимы для большей выборки вариантов столкновений капель с широкими диапазонами изменения их размеров, скоростей движения и углов атаки. Диапазоны варьирования параметров капель были следующими: размеры (условные радиусы) $0.1-1 \mathrm{~mm}$, скорости движения $0.1-10 \mathrm{~m} / \mathrm{s}$, углы столкновения $0-\pi / 2$.

Регистрация процессов столкновений капель осуществлялась высокоскоростной видеокамерой (разрешение $1152 \times 864$, частота 10000 кадров в секунду), расположение которой относительно области смешения потоков изменялось в серии опытов для получения пространственных видеограмм. Типичные кадры с изображением сближающихся и сталкивающихся капель приведены на рисунке для разных конфигураций поверхностей: сфера, вытянутый и сплюснутый эллипсоиды. Разновидностей форм и их положений в процессе полета может быть довольно много (например, в [8,9] приведено 6-8 типичных конфигураций), но в опытах $[8,9]$ отмечено, что в форме сферы, вытянутого или сплюснутого эллипсоида капля находится в течение $70-80 \%$ от времени полета.

Аналогично опытам [6,7] выполнялась выборка кадров, на которых зафиксированы процессы сближения капель в газовой среде. Все столкновения разделены на три группы, для каждой из которых регистрировалось доминирование одного из трех вариантов последствий: коагуляция (слияние), разлет (соударение, при котором образуются две капли с размерами, соответствующими начальным), дробление (измельчение). Рассчитывались частоты реализации конкретного вида последствий при идентичных параметрах столкновений к общему числу последних: $P_{1}-$ коагуляция, $P_{2}-$ разлет, $P_{3}$ - дробление. Сумма значений $P_{1}, P_{2}, P_{3}$ равнялась 1 . Анализ проводился при обработке не менее 100 взаимодействий капель при идентичных условиях.

По результатам опытов получены зависимости значений $P_{1}, P_{2}, P_{3}$ от размеров $R_{d}$, скоростей движения $U_{d}$ и углов столкновений $\alpha_{d}$, как в эксперимен- 

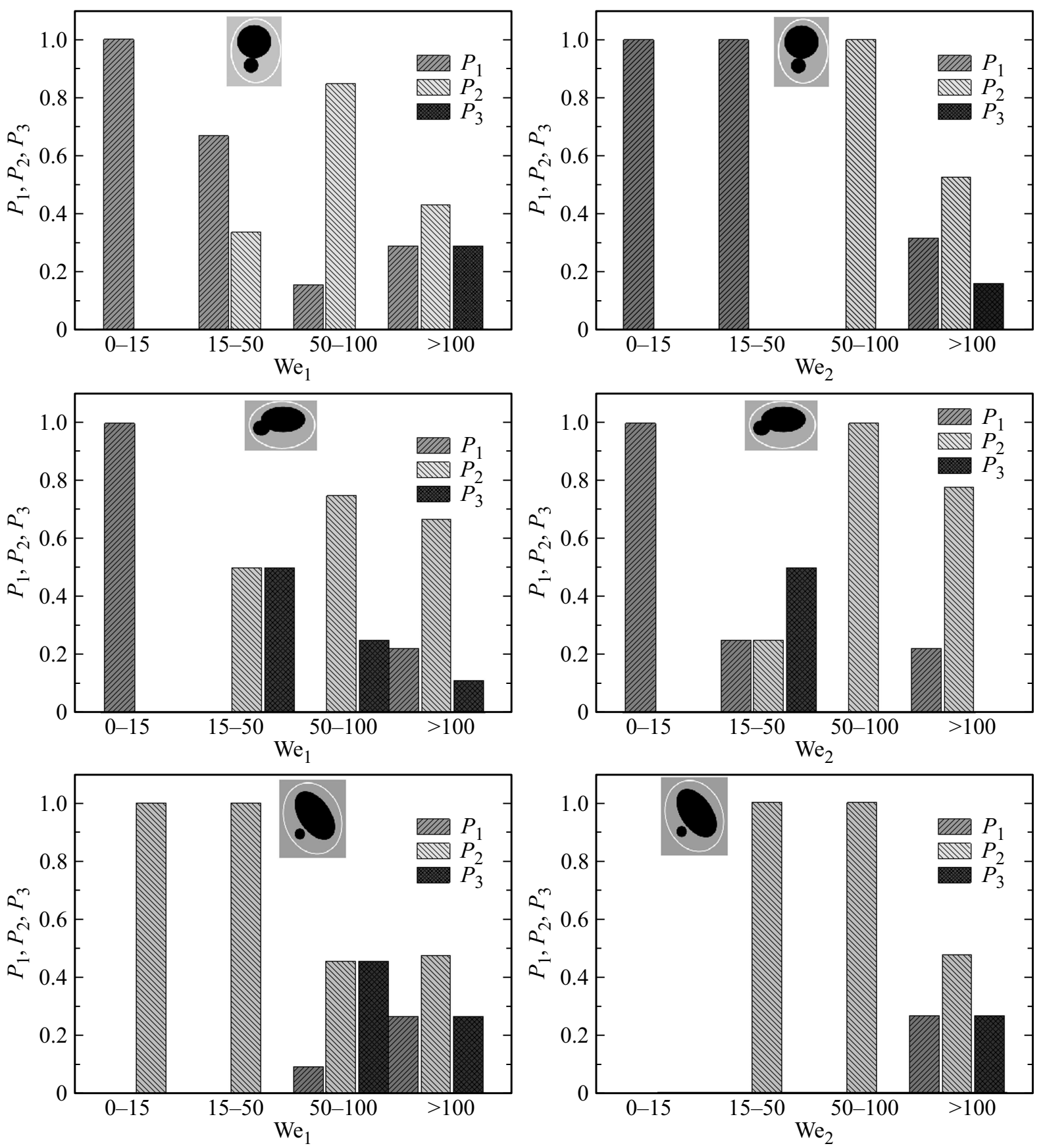

Значения частоты реализации последствий столкновений капель разной формы в зависимости от числа Вебера (We 1 снаряд, $\mathrm{We}_{2}-$ мишень, $P_{1}-$ коагуляция, $P_{2}-$ разлет, $P_{3}-$ дробление): верхний ряд - сфера - сфера, средний ряд - сфера - вытянутый эллипсоид, нижний ряд - сфера-сплюснутый эллипсоид.

$\operatorname{tax}[6,7]$. На основе этих зависимостей рассчитаны числа Вебера сближающихся капель перед столкновением с учетом относительной скорости встречного движения $U_{d}=\left(\left|U_{d 1}\right|^{2}+\left|U_{d 2}\right|^{2}-2\left|U_{d 1}\right| \cdot\left|U_{d 2}\right| \cdot \cos \left(\alpha_{d}\right)\right)^{0.5}: \quad \mathrm{We}_{1}=$ $=2 \rho R_{d 1}\left|U_{d}\right|^{2} / \sigma, \mathrm{We}_{2}=2 \rho R_{d 2}\left|U_{d}\right|^{2} / \sigma$. Значения $U_{d 1}, U_{d 2}$, $R_{d 1}, R_{d 2}$ определялись исходя из видеограмм опытов. Методики проведения экспериментов и погрешности измерений соответствовали [6,7]. Выполнялось разделение всех изображений регистрируемых капель по их формам за счет сравнения с принятой эталонной формой. Допускались отклонения по средним размерам не более чем на $5 \%$. Свойства воды задавались в соответствии с ранними экспериментами [4-7] для $20^{\circ} \mathrm{C}$ : плотность $\rho=10^{3} \mathrm{~kg} / \mathrm{m}^{3}$, поверхностное натяжение $\sigma=72.88 \cdot 10^{-3} \mathrm{~kg} / \mathrm{s}^{2}$.

На рисунке представлены соответствующие проведенным экспериментам значения $P_{1}, P_{2}, P_{3}$ для широкого диапазона $\alpha_{d}=0-\pi / 2$ аналогично опытам [4-6]. На 
рисунке приведены значения $P_{1}, P_{2}, P_{3}$ при изменении $\mathrm{We}_{1}$ и $\mathrm{We}_{2}$ для разных форм капель (во всех случаях капля-снаряд была близка по форме к сфеpe, а мишень имела конфигурацию сферы, вытянутого или сплюснутого эллипсоида). В случае столкновений сфера-сфера в широком диапазоне доминировали значения $P_{1}$, соответствующие высокой частоте реализации коагуляции (см. рисунок). В системе сфера-сплюснутый эллипсоид доминировал разлет $\left(P_{2}\right)$. Также высокие значения имел параметр $P_{3}$, отражающий дробление. Видеограммы показали устойчивую зависимость $P_{2}$ и $P_{3}$ от условий столкновений в системе сфера-сплюснутый эллипсоид. В частности, при ударе сферической капли в центральную часть сплюснутого эллипсоида регистрировался разлет капель с сохранением начальных размеров. Если же сферическая капля попадала в боковую часть сплюснутого эллипсоида, то она ее разрушала практически полностью (формировался полидисперсный аэрозоль). При регистрации столкновения капель по схеме сфера-вытянутый эллипсоид доминировали значения $P_{2}$ и, особенно, $P_{3}$, иллюстрирующие условия интенсивного измельчения капель. При снижении скорости движения или размеров капли-снаряда регистрировался рост $P_{2}$. Значения $P_{1}$ были малы во всем диапазоне варьирования $\mathrm{We}_{1}$ и $\mathrm{We}_{2}$.

Значения $P_{1}, P_{2}, P_{3}$ различаются в несколько раз для схем сфера-сфера, сфера-вытянутый эллипсоид, сфера-сплюснутый эллипсоид при идентичных $\mathrm{We}_{1}$ и $\mathrm{We}_{2}$ (см. рисунок). Еще более заметные различия зарегистрированы при рассмотрении взаимодействий капель по схеме эллипсоид-эллипсоид. Условия взаимодействия сплюснутых эллипсоидов отличались наиболее существенно от всех остальных (см. рисунок). Это связано с неустойчивостью поверхности тел в такой форме [8] и разными последствиями ударов капель. В частности, опыты показали, что сплюснутые эллипсоиды интенсивно тормозились в потоке воздуха (скорости движения снижались в несколько раз) по сравнению со сферами и вытянутыми эллипсоидами. Это обусловлено высокими значениями коэффициентов аэродинамического сопротивления $c_{d}$ (в среднем в $1.2-1.6$ раза выше по сравнению со сферами и в 1.5-2.1 выше, чем у вытянутых эллипсоидов [8-10]). Как следствие, аэродинамические силы, действующие на сплюснутые эллипсоиды, существенно выше [10]. Также значительное влияние оказывали различия между положением центров масс капель разной конфигурации. Лишь при максимальных размерах и малых скоростях движения сплюснутых эллипсоидов регистрировались единичные случаи коагуляции (см. рисунок). Таким образом, для интенсификации дробления капель важно организовать трансформацию их поверхности за счет их вращения, импульсной подачи, вибраций или других эффектов, описанных в [8-10].

При сравнительном анализе рисунка и известных данных о предельных числах Вебера для разных последствий столкновений, например в случае взаимодей- ствия двух капель $[4,5]$ или элементов аэрозоля [6,7], можно сделать вывод, что лишь для схем сфера-сфера установлено удовлетворительное соответствие. В частности, различия переходных (между режимами взаимодействия) значений $\mathrm{We}_{1}$ и $\mathrm{We}_{2}$ не превышали $10-20 \%$. В частности, на основе результатов опытов [4-7] было отмечено, что при $0<\mathrm{We}<0.5$ капли сливались под действием сил поверхностного натяжения; при $0.5<\mathrm{We}<1.5$ регистрировался отскок (за счет газовой прослойки между ними); для диапазона $1.5<\mathrm{We}<15$ характерна коагуляция; интервал $15<\mathrm{We}<50$ соответствует разлету капель; при $50<\mathrm{We}<100$ регистрировались разлеты и дробление в зависимости от расположения центров масс взаимодействующих капель; при $\mathrm{We}>100$ происходило устойчивое дробление. В экспериментах установлено, что для эллипсоидов существенно меньше предельные значения $\mathrm{We}_{1}$ и $\mathrm{We}_{2}$, соответствующие разлетам и дроблению (см. рисунок). Лишь при коагуляции переходные значения чисел Вебера были близки для разных рассмотренных форм при малых скоростях и размерах капель. Значимость результатов выполненных экспериментов состоит в том, что установлены различия значений $\mathrm{We}_{1}$ и $\mathrm{We}_{2}$, соответствующие наиболее типичным конфигурациям поверхности капель. Предельные числа Вебера для перехода от коагуляции к разлету сферических капель составили 15-25. В случае сфера-вытянутый эллипсоид эти же значения составили 10-18, а в случае сфера-сплюснутый эллипсоид уже 7-11. Если учесть, что значения коэффициентов аэродинамического сопротивления меняются для капель разной формы от 0.24 до 0.56 [8-10], то очевидна связь $c_{d}$ и $P_{1}, P_{2}, P_{3}$. Важно с учетом разных форм обеих сталкивающихся капель в дальнейшем описать данную связь математически. При этом целесообразно провести уточняющие эксперименты с жидкостями и газами, имеющими свойства, существенно отличающиеся от свойств воды и воздуха соответственно (для учета вязкости, плотности, поверхностного натяжения). В таком случае можно выделить корректирующий коэффициент для переходных (между коагуляцией, разлетом, дроблением) чисел Вебера, который учитывает аэродинамический коэффициент.

В нашем исследовании обобщены результаты экспериментов при столкновениях капель в воздухе без нагрева в отличие от опытов [6,7], в которых капельный аэрозоль впрыскивался во встречный поток высокотемпературных (до $1000^{\circ} \mathrm{C}$ ) продуктов сгорания. В опытах [6,7] доминировала коагуляция сталкивающихся капель. С учетом полученных в настоящей работе результатов можно сформулировать дополнительные пояснения причин высоких значений $P_{1}$ в экспериментах [6,7]. Во-первых, встречный поток продуктов сгорания существенно тормозил капли. Во-вторых, высокие температуры интенсифицировали испарение, уменьшение размеров и приближение к сферическим формам капель. В-третьих, турбулентные пульсации продуктов сгорания хаотично смещали и 
закручивали капли. Как следствие, вероятность встречных столкновений капель с высокой относительной скоростью была мала. Поэтому в опытах [6,7] значения $P_{2}$ и тем более $P_{3}$ были существенно меньше $P_{1}$. Но тем не менее даже при малых значениях $\mathrm{We}_{1}$ и $\mathrm{We}_{2}$ роль формы капель высока (см. рисунок). В опытах с двумя каплями $[4,5]$ и аэрозолем $[6,7]$ учет формы привел бы к существенному изменению $P_{1}, P_{2}, P_{3}$ как функций $\mathrm{We}_{1}$ и $\mathrm{We}_{2}$.

Таким образом, проведенные эксперименты показали неполное соответствие современной теории взаимодействия капель жидкостей в газовой среде [1-3,6-10] реальным процессам их столкновений. Это обусловлено тем, что положения $[1-3,6-10]$ опираются на три основных фактора (размеры, скорости движения и угол взаимодействия), но не учитывают возможное влияние формы капель. При близких значениях чисел Вебера могут реализоваться разные последствия столкновений капель в зависимости от конфигурации их поверхностей (см. рисунок), что важно учитывать в газопарокапельных приложениях [10] при настройке систем распыления.

Исследование выполнено за счет средств гранта Российского научного фонда (проект № 18-71-10002).

\section{Список литературы}

[1] Фукс Н.А. Механика аэрозолей. М.: Изд-во АН СССР, 1955. $353 \mathrm{c}$.

[2] Пажси Д.Г., Галустов В.С. Основы техники распыливания жидкостей. М.: Химия, 1984. $256 \mathrm{c.}$

[3] Нигматулин Р.И. Динамика многофазных сред. М.: Наука, 1987. $464 \mathrm{c}$.

[4] Архипов В.А., Ратанов Г.С., Трофимов В.Ф. // ПМТФ. 1978. № 2. C. 73-77.

[5] Архипов В.А., Васенин И.М., Трофимов В.Ф. // ПМТФ. 1983. № 3. C. 95-98.

[6] Кузнецов Г.В., Волков Р.С., Стрижсак П.А. // Письма в ЖТФ. 2015. Т. 41. В. 17. С. 53-60.

[7] Антонов Д.В., Волков Р.С., Кузнецов Г.В., Стрижсак П.А. // Инж.-физ. журн. 2016. Т. 89. № 1. С. 94-103.

[8] Volkov R.S., Kuznetsov G.V., Strizhak P.A. // Int. J. Heat Mass Transf. 2015. V. 85. P. 1-11.

[9] Shreiber A.A., Podvysotsky A.M., Dubrovsky V.V. // Atom. Sprays. 1996. V. 6. N 6. P. 667-692.

[10] Высокоморная О.В., Кузнецов Г.В., Стрижсак П.А. Испарение и трансформация капель и больших массивов жидкости при движении через высокотемпературные газы. Новосибирск: Изд-во СО РАН, 2016. 302 с. 